\title{
Implementation of Disruptive Designs for Gas Turbine Components Utilizing Additive Manufacturing
}

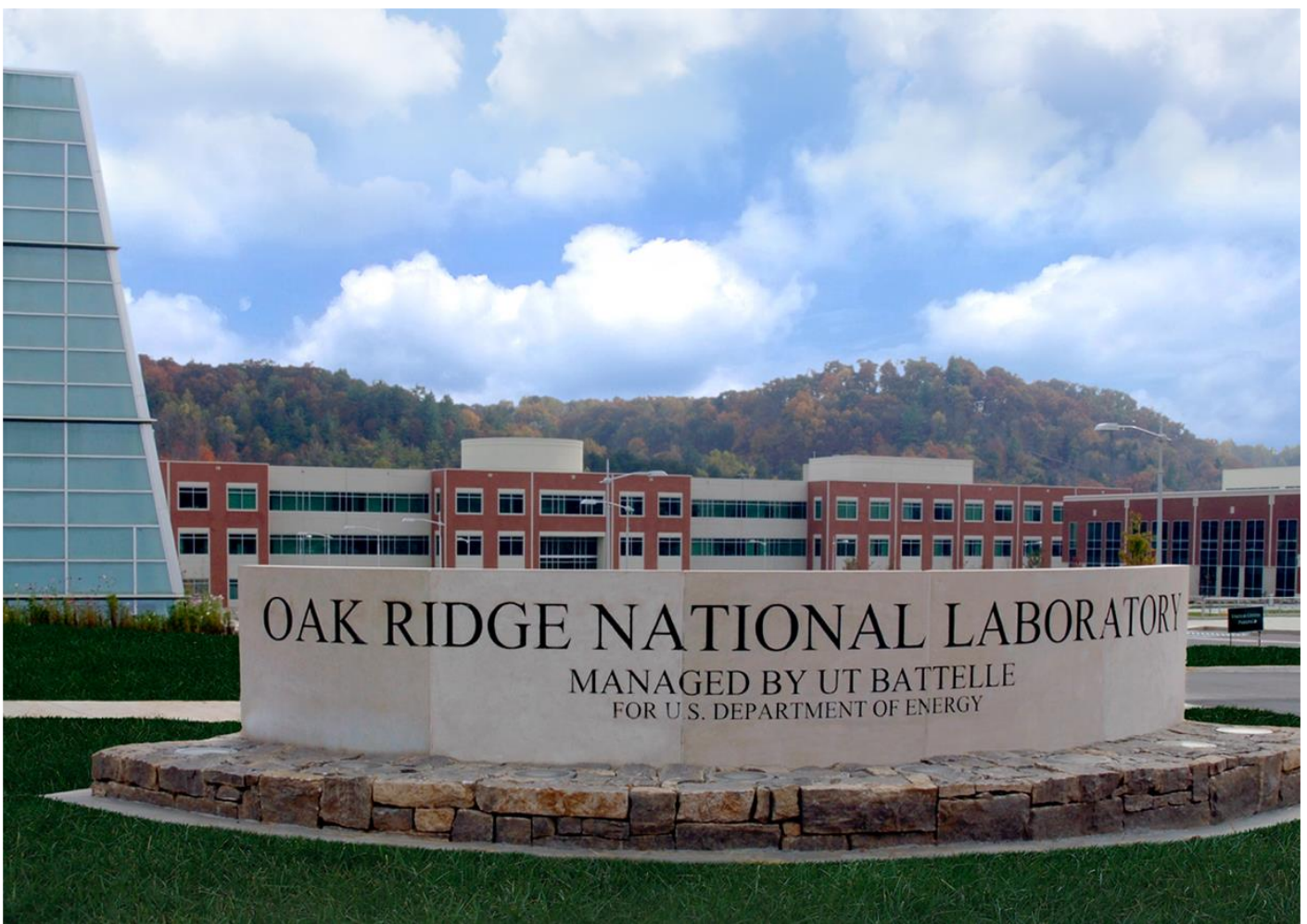

\section{CRADA FINAL REPORT NFE-19-07703}

Approved for Public Release. Distribution is Unlimited.
Yousub Lee Michael Kirka Srdjan Simunovic Patxi Fernandez-Zelaia Kyle Stoodt Anand Kulkarni

February 03, 2021 


\section{DOCUMENT AVAILABILITY}

Reports produced after January 1, 1996, are generally available free via US Department of Energy (DOE) SciTech Connect.

Website http://www.osti.gov/scitech/

Reports produced before January 1, 1996, may be purchased by members of the public from the following source:

National Technical Information Service

5285 Port Royal Road

Springfield, VA 22161

Telephone 703-605-6000 (1-800-553-6847)

TDD 703-487-4639

Fax 703-605-6900

E-mail info@ntis.gov

Website http://www.ntis.gov/help/ordermethods.aspx

Reports are available to DOE employees, DOE contractors, Energy Technology Data Exchange representatives, and International Nuclear Information System representatives from the following source:

Office of Scientific and Technical Information

PO Box 62

Oak Ridge, TN 37831

Telephone 865-576-8401

Fax 865-576-5728

E-mail reports@osti.gov

Website http://www.osti.gov/contact.html

This report was prepared as an account of work sponsored by an agency of the United States Government. Neither the United States Government nor any agency thereof, nor any of their employees, makes any warranty, express or implied, or assumes any legal liability or responsibility for the accuracy, completeness, or usefulness of any information, apparatus, product, or process disclosed, or represents that its use would not infringe privately owned rights. Reference herein to any specific commercial product, process, or service by trade name, trademark, manufacturer, or otherwise, does not necessarily constitute or imply its endorsement, recommendation, or favoring by the United States Government or any agency thereof. The views and opinions of authors expressed herein do not necessarily state or reflect those of the United States Government or any agency thereof. 
ORNL/TM-2021/2060

CRADA/NFE-19-07703

Material Science and Technology Division

Computational Sciences and Engineering Division

Advanced Manufacturing Office

\title{
Implementation of Disruptive Designs for Gas Turbine Components Utilizing Additive Manufacturing
}

\author{
Yousub Lee \\ Michael Kirka \\ Srdjan Simunovic \\ Patxi Fernandez-Zelaia \\ Kyle Stoodt (Siemens) \\ Anand Kulkarni (Siemens)
}

Date Published: February 21, 2021

\author{
Prepared by \\ OAK RIDGE NATIONAL LABORATORY \\ Oak Ridge, Tennessee 37831-6283 \\ managed by \\ UT-BATTELLE, LLC \\ for the \\ US DEPARTMENT OF ENERGY \\ under contract DE-AC05-00OR22725
}

Approved for Public Release 


\section{CONTENTS}

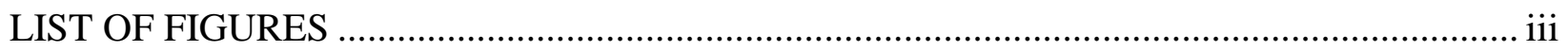

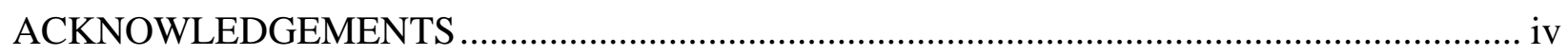

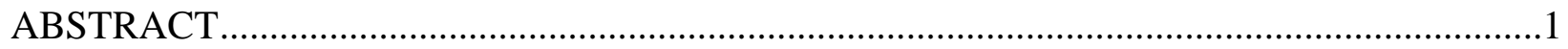

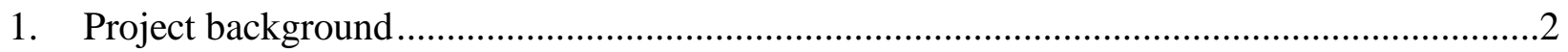

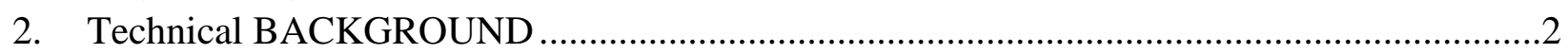

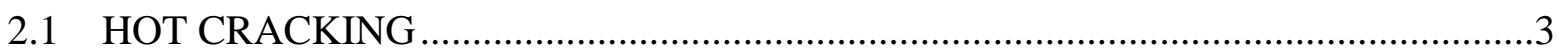

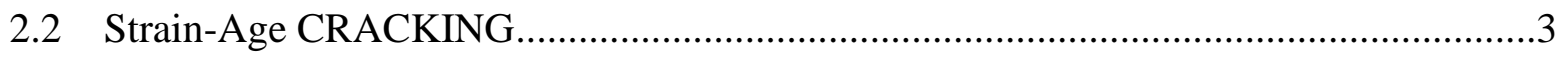

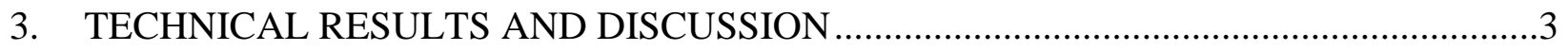

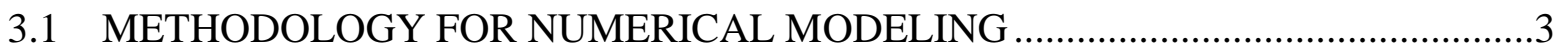

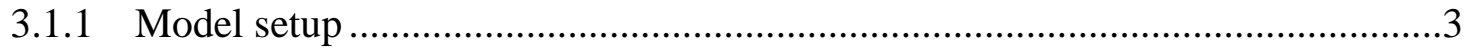

3.1.2 Microstructure modeling .............................................................................

3.2 Effect of process parameters and part geometry on Cracking susceptibility ……...........7

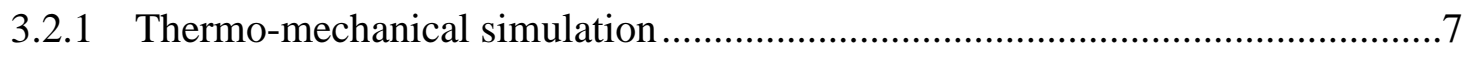

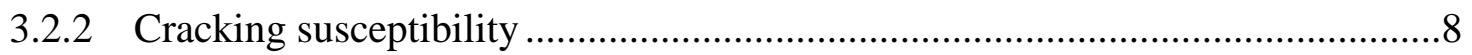

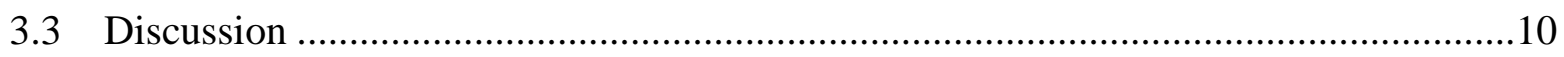

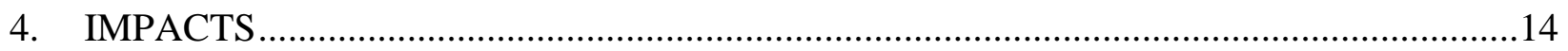

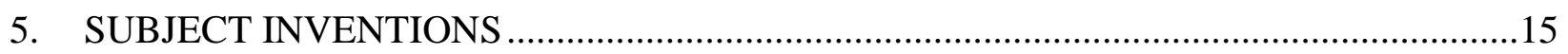

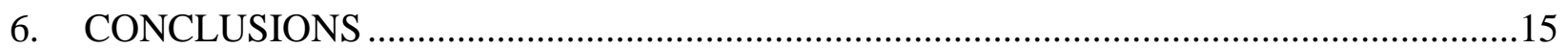

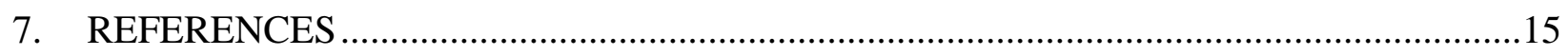




\section{LIST OF FIGURES}

Figure 1. Types of cracking in Ni-based superalloy. Hot cracking is associated with a liquid film, while solid-state cracking is associated with precipitates.

Figure 2. Two blade geometries used in the simulation, (a) Blade-1 (thin), and (b) Blade-2 (thick)

Figure 3. Complex geometry and hexa-meshing using CUBIT ..............................................5

Figure 4. Example of time-temperature-transformation (TTT) diagram .....................................5

Figure 5. Evolution of stress in blade-1. Higher stress is observed in the upper region.................7

Figure 6. (a) Blade geometry and monitoring location (b) predicted thermal history and (c) corresponding evolution of maximum principal stress at the monitoring location (=39 mm up from the base plate) ..............................................................

Figure 7. Thermal-microstructure-stress response in the blade- 1 .............................................. 9

Figure 8. Dynamic evolution of thermal-microstructure-stress in the blade-2 ...........................10

Figure 9. Category of printable, processible, and non-printable Ni-based superalloys, (a) in EBM at ORNL and (b) in welding literature

Figure 10. TTT diagram for printable, processible, and non-printable alloys, (a) HastelloyX (printable), (b) IN738LC (processible), (c) CM-247LC (processible but limited), and (d) Mar-M247 (non-printable).

Figure 11. Comparison of Mar-M247 to IN738 in thermal-microstructure-stress response .13

Figure 12. TTT diagram of In738 and Mar-M247. The nose of the curve is pushed to the right region by addition of Co 


\section{ACKNOWLEDGEMENTS}

This CRADA NFE-19-07703 was conducted as a Technical Collaboration project within the Oak Ridge National Laboratory (ORNL) Manufacturing Demonstration Facility (MDF) sponsored by the US Department of Energy Advanced Manufacturing Office (CPS Agreement Number 24761). Opportunities for MDF technical collaborations are listed in the announcement "Manufacturing Demonstration Facility Technology Collaborations for US Manufacturers in Advanced Manufacturing and Materials Technologies" posted at http://web.ornl.gov/sci/manufacturing/docs/FBO-ORNL-MDF-2013-2.pdf. The goal of technical collaborations is to engage industry partners to participate in short-term, collaborative projects within the Manufacturing Demonstration Facility (MDF) to assess applicability and of new energy efficient manufacturing technologies. Research sponsored by the U.S. Department of Energy, Office of Energy Efficiency and Renewable Energy, Advanced Manufacturing Office, under contract DEAC05-00OR22725 with UT-Battelle, LLC. 


\begin{abstract}
Electron beam melting (EBM) is an additive manufacturing process used to print metallic components with complex geometries for aerospace applications. A preheating characteristic enables this technology to avoid large accumulation of residual stress during printing. However, cracking mechanisms particularly in Ni-based superalloys are associated with not only residual stress but also with microstructure (i.e., solidification morphology, transient evolution of $\gamma^{\prime}$ ). Siemens is committed to AM technology for gas turbine applications. The ability to novel predictive designs of turbine blades would reduce process development time and allow acquisition of key microstructure and performance data early in a design campaign. Siemens initiated a project to establish the design rules for the fabrication of non-printable Nibased superalloys. This phase 1 program demonstrates the feasibility for virtual fabrication of the actual blade geometries through EBM process.
\end{abstract}




\section{PROJECT BACKGROUND}

This phase 1 Cooperative Research and Development Agreement (CRADA-NFE-19-07703) with Siemens Corporation begun in October, 2019 and was completed on October, 2020. Through the development efforts of this program, ORNL and Siemens were able to establish the design rules for the fabrication of the traditionally non-printable Ni-based superalloys throught modeling of the electron beam melting (EBM) additive manufacturing (AM) process.

\section{TECHNICAL BACKGROUND}

Ni-based superalloys have been broadly used for the last three decades in gas turbine and aerospace industries due to their superior high-temperature properties such as high tensile strength, high-temperature creep behavior, and hot corrosion resistance. Many Ni-based superalloys have poor printability due to various cracking mechanisms. i.e., solidification cracking, liquation cracking, strain-age cracking, and ductility dip cracking [1,2]. Those cracks form independently or simultaneously during printing and postheat treatment. Figure 1 shows a descriptive illustration of cracking types in Ni-based superalloy. The hot cracking typically forms during solidification and is associated with liquid film at the grain boundary. The solid-state cracking happens in the solid-phase, so it occurs below solidus temperature. The solid-state cracking is often associated with $\gamma^{\prime}$ in Ni-based superalloys. The cracking driver involves 1) solute partitioning, 2) precipitation kinetics, 3) thermal stresses resulting from rapid heating and cooling, and 4) the presence of residual stress bought about by the thermal gradient. Also, AM involves complex and varying geometries such that complex interactions are produced between process, part geometry, and cracking susceptibility. The assessment of cracking susceptibility requires exhaustive experimental charaterization that challenges the raid design and qualification of the component.

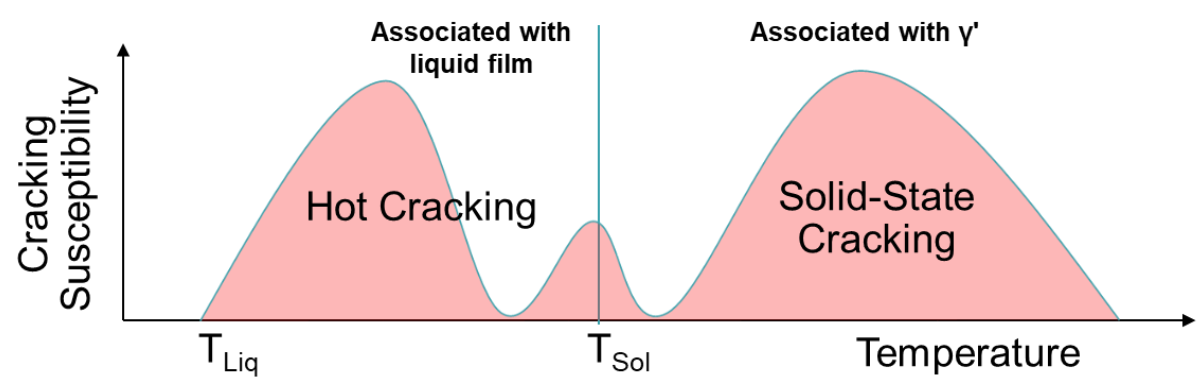

Figure 1. Types of cracking in Ni-based superalloy. Hot cracking is associated with a liquid film, while solid-state cracking is associated with precipitates.

The goal of this project is to improve the EBM printability on the crack-prone high $\gamma^{\prime}$ Ni-based superalloys with realisic geometries for fabricating industrial gas turbine components. In this research, thermal stress calculation was performed using finite element method (FEM) code. Also, solid-state phase transformation kinetics, i.e., diffusional, non-diffusional, and reversible phase transformation were considered based on the Time-Temperature-Transformation (TTT) diagram. As a result, the fractional changes in $\gamma^{\prime}$ precipitate and stress evolution were predicted during a part printing. The outline of this report is as follows. Section 2 shows theretical cracking mechanisms of Ni-based superalloys found in prior welding and AM literature. Section 3 shows the modeling methodologies and the results for 
determination of crakcing susceptiblity. Additionally, an alloy design approach to improve the printability is proposed in section 3. The impact and conclusion from current work are given in section 4, 5, and 6 .

\subsection{HOT CRACKING}

Ni-based superalloys contain several alloying elements (e.g., Al, Ti, Nb, B, W, Ta, Co, Cr etc.) to improve grain boundary statiblity by inducing carbide and to optimize size and shape of $\gamma^{\prime}$ precipitate through heat treatment . However, these additions of alloying elements leads to solute partitioning during solidification at different magnitudes between solid and liquid [2]. The solute partitioning widens the solidification temeperature range known as mushy zone. It is generally believed that larger solidification temperature range increases the propensity of hot cracking since the liquid film can be present longer at lower temperatures [3]. The hot cracking occurs during solidificaiton when the mushy zone is upon high solid fraction and tensile stress. The liquid film present at the grain boundary cannot accommodate the tensile stress and consequently it causes the hot cracking during printing. It can be minimized by avoiding simultaneous occurance of high tensile stress and liquid film formation. The microstructure manipulation forming equiaxed grain also could effectively reduce the chance of hot cracking [2-5].

\subsection{STRAIN-AGE CRACKING}

For most Ni-based superalloys, solid-state cracking is generally associated with the formation of $\gamma^{\prime}$ precipitate. Particularily, the strain-age cracking occurs when the precipitation hardening overlaps intrinsic and extrinsic strain accumulation [6]. The precipitation hardening increases the strength of grain, but consumes ductility. The precipiation in the grain results in corresponding formation of precipitate free zone (PFZ) at or near the grain boudary. When the sufficient strain is applied to the material, the cracking occurs at or near the grain boudary. In general, it is believed that higher Ti and Al concentration tends to increase the susceptibility of strain-age cracking. The fraction of $\gamma^{\prime}$ precipitate and the precipitation rate also have a signifiant impact on the cracking susceptibility. Since a higher fraction of $\gamma^{\prime}$ exhibits lower ductility, tracking changes in the fraction is benefitial for determination of the cracking susceptibility. For instance, the ductility can be dropped to $2 \%$ in elongation at $30 \%$ of $\gamma^{\prime}$ precipitate [7]. It is known that IN718 is quiet resistance to strain-age carcking due to relatively slower precipitation rate compared to other Ni-based superalloys such as Waspaloy, IN738, and Mar-M247. Note that the actual fraction and rate of precipitates would depend on thermal conditions and precipitation kinetics. The variations across alloys, process conditions, and geometries should be considered and further examined to mitigate the strain-age cracking in Ni-based superalloys.

\section{TECHNICAL RESULTS AND DISCUSSION}

\subsection{METHODOLOGY FOR NUMERICAL MODELING}

\subsubsection{Model setup}

Two blade geometries were selected to investigate the gemetric influence on cracking susceptibility. The blade dimensions are $40 \mathrm{~mm}(\mathrm{~W}) \times 6.5 \mathrm{~mm}(\mathrm{~T}) \times 64.8 \mathrm{~mm}(\mathrm{H})$ for blade- 1 and $41 \mathrm{~mm}(\mathrm{~W}) \times 14.5$ $\mathrm{mm}(\mathrm{T}) \times 64.8 \mathrm{~mm}(\mathrm{H})$ for blade-2 in Fig. 2 . The blade-2 is about twice thicker than the blade-1. As noticed, the blade- 2 has more complex geometric features due to cooling channels. 

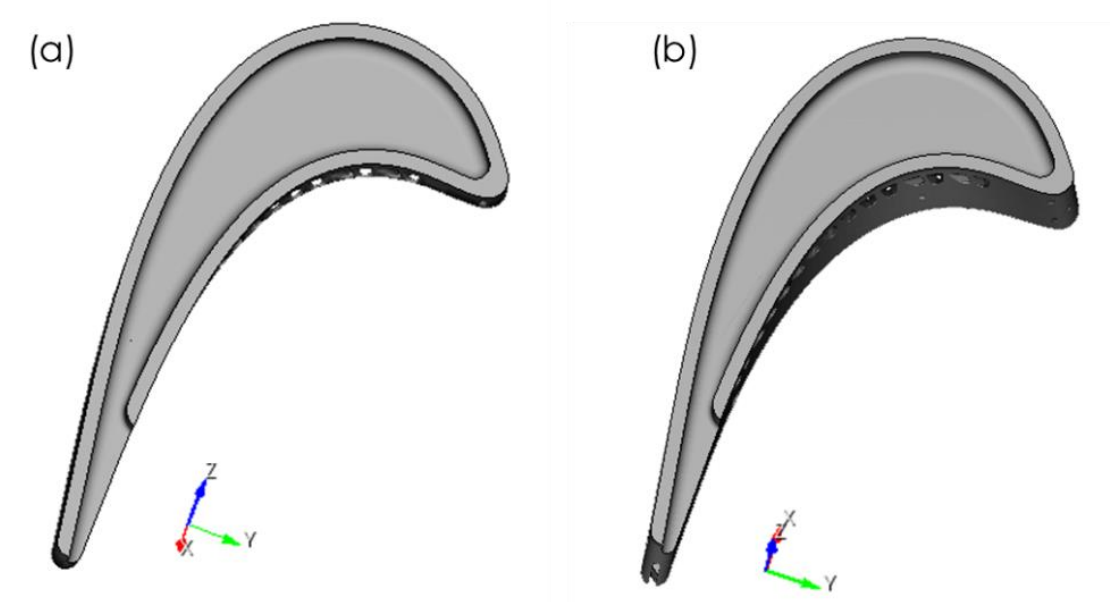

Figure 2. Two blade geometries used in the simulation, (a) Blade-1 (thin), and (b) Blade-2 (thick)

The computation domain was created using a mesh and geometry generation toolkit CUBIT by Sandia National Laboratory. As recognized, the blade geometry is highly complex such that generation of hexahedral mesh is typically considered to be difficult and time-consuming job. Sculpt, a separate companion application in the CUBIT, allows generation of all hexahedron elements by using grid-based method [8] Since AM creates part layer by layer, generation of flat top surface by using hexahedron elements improves simulation quality compared to a typical model consisting of tetrahedron elements in Fig.3. The characteristic mesh size was approximately $170 \mu \mathrm{m}$ for the blade. A significantly large mesh of $5 \mathrm{~mm}$ was used for the substrate for better computational efficiency. The model has 425,650 elements 3D 8 node linear hexahedron elements for heat transfer (DC3D8) and stress (C3D8) analyses.

Figure 3 shows the blade- 1 geometry and magnified hexahedron elements after meshing. The bottom of the blade part is fused on the start plate. Hence, the bottom nodes are fully constrained in all x-, y-, and z-direction during the simulation. Overhanging structure with high building angle considered here typically requires support structures that provides additional constraints on the bottom surface of the part contacting to the support.

Two virtual scan paths were created to demonstrate a feasibility of digital manufacturing framework prior to actual printing and then converted to the scan path for simulation. The scan path includes dynamic variation of process parameters such as power, speed, and beam position. Since the part is built in the vacuum environment, the beam absorptance of 0.9 is assumed and only heat loss by radiation is considered within emissivity of 0.6 . 


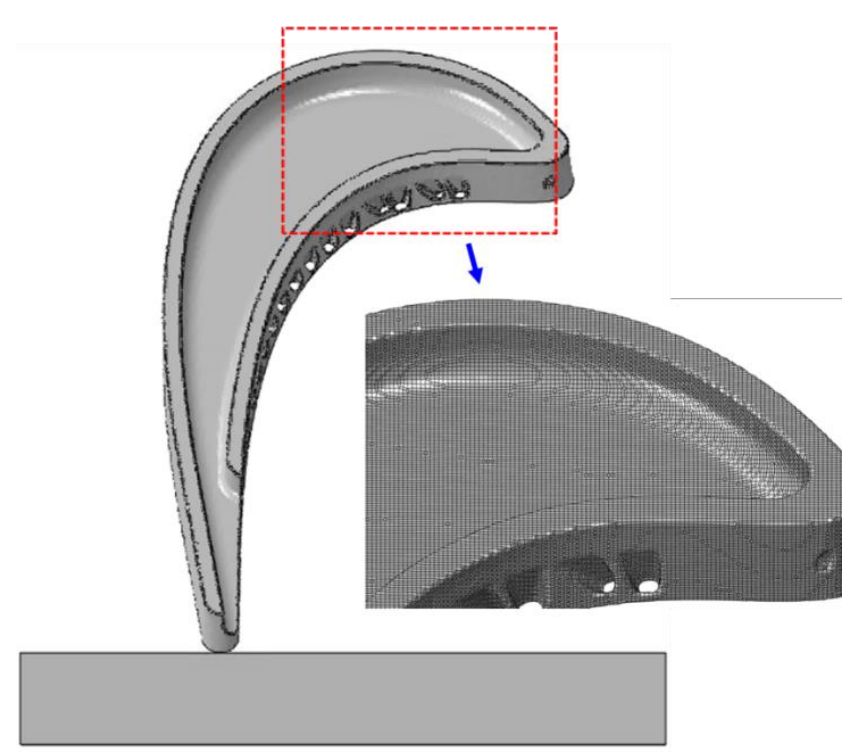

Figure 3. Complex geometry and hexa-meshing using CUBIT

\subsubsection{Microstructure modeling}

A complex thermal cycle brings about spatial and temporal variations in microstructure and resultant mechanical properties. The microstructural variations are strongly correlated with process parameters, scan path, and part geometry, which can be easily extended to an optimization scheme including post-heat treatment. Microstructure control for non-printable Ni-based superalloy heavily involves control of the faction and rate of $Y^{\prime}$ during printing or post-heat treatment. The microstructure modeling accounts for solid-state phase transformations induced by multiple thermal cycles. Onset and rate of precipitate are associated with each alloy's TTT diagram that can be measured by Jominy test [9] or predicted using CLAPHAD methods such as Thermocalc [10] and JMatPro [11]. Figure 4 shows an example of timetemperature-transformation (TTT) diagram that can include diffusional transformation $\left(\mathrm{D}_{\mathrm{s}}\right.$ for start and $\mathrm{D}_{\mathrm{f}}$ for end) and diffusionless transformation ( $\mathrm{M}_{\mathrm{s}}$ for start and $\mathrm{M}_{\mathrm{f}}$ for end).

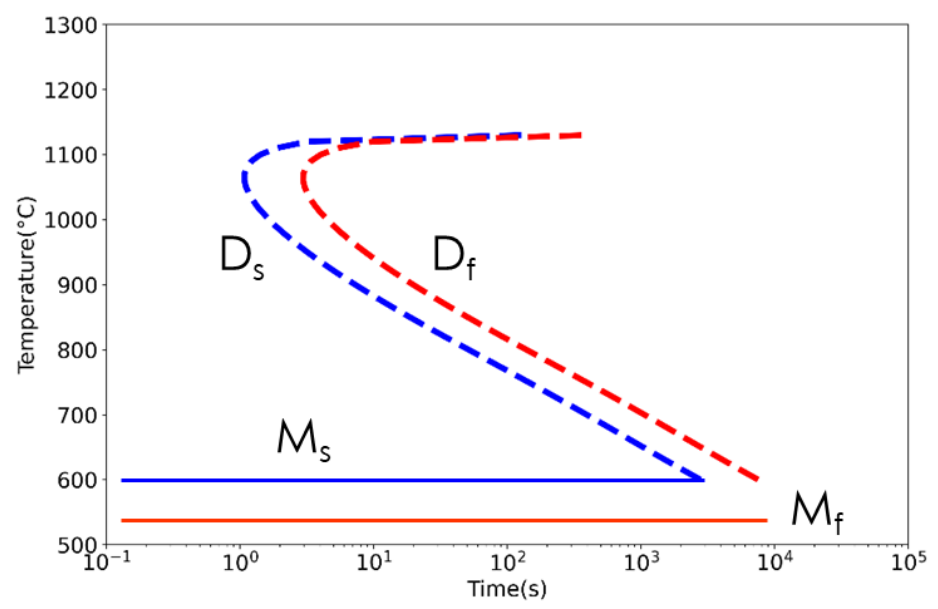

Figure 4. Example of time-temperature-transformation (TTT) diagram

The curve in TTT diagram represents the initial and final time of isothermal phase transformations at given temperatures. Thus, the volume fraction of a certain phase can be calculated by the time and 
temperature when the transformation occurs. The kinetics of diffusional transformation can be described by the Johnson-Mehl-Avrami (JMA) model $[12,13]$. Detailed algorithms and equations used for microstructure modeling can be found in prior literature [12-14]. The initial $X_{i}$ and end $X_{f}$ of phase fraction are given in Equation (1) and (2). The transformation rate, $\dot{X}(t)$ can be rewritten by the subtraction $X_{i}$ from $X_{f}$ in Equation (3):

$$
\begin{aligned}
X_{i} & =1-e^{-k t_{i}^{p}} \\
X_{f} & =1-e^{-k t_{f}^{p}} \\
\dot{X}(t) & =k p t^{p-1} e^{-k t^{p}}
\end{aligned}
$$

where $k$ is material parameter controlling the duration of phase transformation, $p$ is material parameter controlling the speed of phase transformation and $t$ is time.

For the EBM process, the phase transformations are not isothermal due to iterative rapid heating and cooling. Therefore, an extended JMA model is adopted to consider non-isothermal transformation using additively rule $[12,13]$. The model describes continuous temperature variation as a series of small consecutive isothermal steps. The overall phase evolution can be computed by summation of contributed fractions calculated from each time step. The mathematical expressions are given in Equation (4) and (5).

$$
\begin{gathered}
\Delta X=\dot{X}(T) \Delta t \\
X^{n+1}=X^{n}+\Delta X
\end{gathered}
$$

Diffusionless (=martensitic) transformation is estimated using the empirical Koistinen-Marburger (KM) model [13]. Since the martensitic transformation is independent on time, the change of martensite in the fraction $X_{m}$ can be simply calculated from $\mathrm{M}_{\mathrm{s}}$ temperature and material constant.

$$
X_{m}=\left[1-e^{-k_{m}\left(M_{s}-T\right)}\right] X_{\beta}
$$

where $X_{\beta}$ is amount of phase available for martensitic transformation at Ms, $k_{m}$ is transformation coefficient calibrated from TTT diagram. 


\subsection{EFFECT OF PROCESS PARAMETERS AND PART GEOMETRY ON CRACKING SUSCEPTIBILITY}

\subsubsection{Thermo-mechanical simulation}

To understand the correlation between process parameters, part geometry, and cracking susceptibility, it is important to examine the spatial and temporal evolution of temperature, stress, and microstructure over the part. The sequentially coupled thermo-mechanical model was used in this work. It was presumed that the mechanical stress did not affect temperature evolution and metallurgical phase transformation. Figure 5 shows the evolution of stress in the blade-1. The magnitude of stress increases as the deposition progresses.

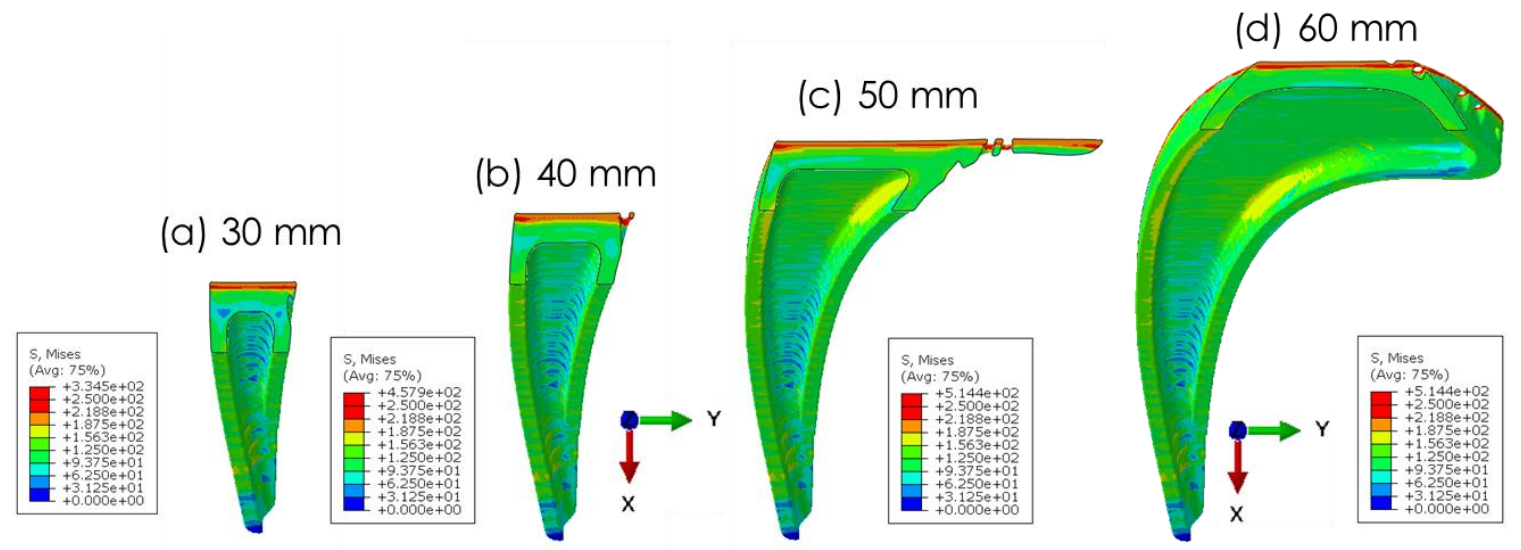

Figure 5. Evolution of stress in blade-1. Higher stress is observed in the upper region.

Figure 6 shows the predicted thermal history and corresponding evolution of maximum principal stress at the monitoring location ( $=39 \mathrm{~mm}$ up from the base plate). Since thermal fluctuation occurs in a short period of time due to high beam velocity in the order of $\mathrm{m} / \mathrm{s}$, it merges in long time scale and looks a single heating, but multiple fluctuations are observed in the magnified image with a small time scale in the inset in the Fig. 6(b). The max. principal stress increases as the part temperature drops below solidus temperature and then it slightly rebounds up corresponding temperature fluctuations.
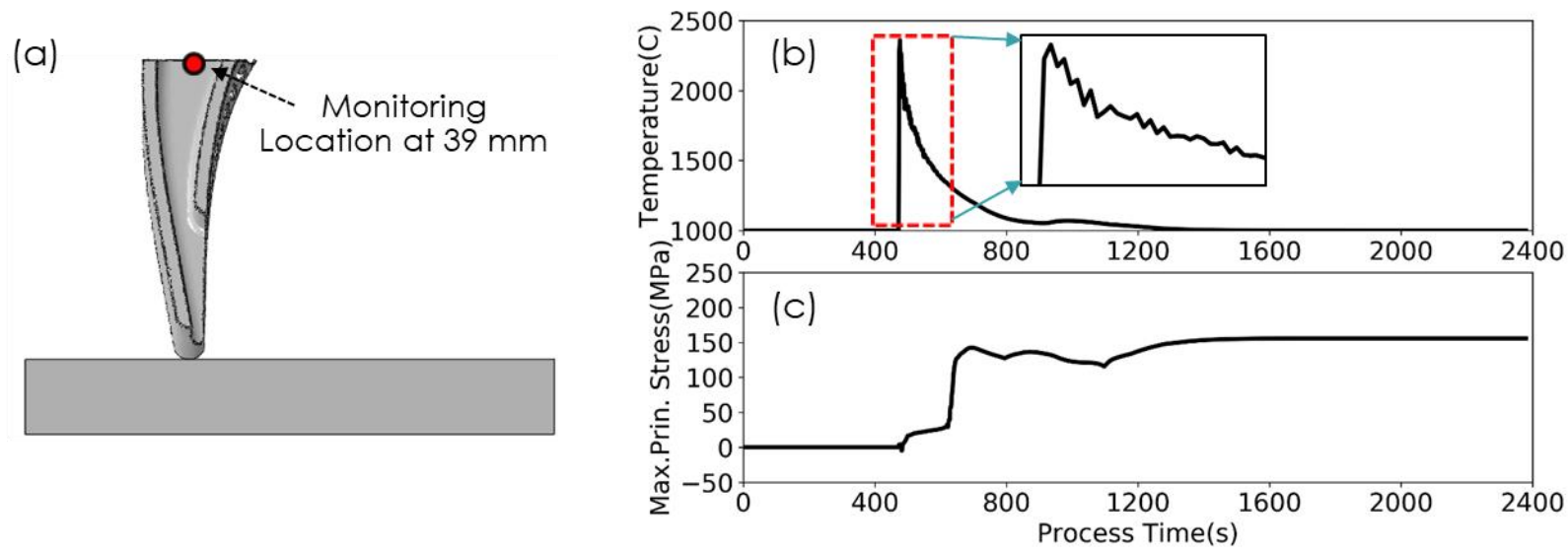

Figure 6. (a) Blade geometry and monitoring location (b) predicted thermal history and (c) corresponding evolution of maximum principal stress at the monitoring location $(=39 \mathrm{~mm}$ up from the base plate) 


\subsubsection{Cracking susceptibility}

Cracking susceptibility of IN738 are evaluated using two cracking criteria for hot-cracking and solidstate cracking from literature [1-3, 6]. The solidification cracking occurs in the reigion where the liquid film and tensile stress coexist during solidification $[2,3,15]$. The cracking initiates and propagates until the end of dendrite coalescence. The susceptible temperature range can be determined through the amout of solid fraction as a function of temperature by the Scheil-Gulliver method using ThermoCalc.[10]. Since the Scheil equation does not examine the coalescence of dendrites, the susceptible solid fraction, which exisits between 0.7 and 0.98 , is empirically defined from prior literature [4]. The corresponding tempetures to these solid fractions are $1145^{\circ} \mathrm{C}$ and $1305^{\circ} \mathrm{C}$, respectively. The susceptible temperature range is represented in the red colored block in Fig.7 and 8. Tensile stress is observed in the susceptible temperature range at both lower and upper height of $39 \mathrm{~mm}$ and $58 \mathrm{~mm}$. It indicates that solidificaiton cracking can be prevalent over the blade- 1 geometry at the printing condition.

The mechanism for strain-age cracking has been widely reported in welding literature $[1,6,7]$, but still the cracking mechanism has not reached to a full consensus yet. However, the generally accepted theory is that the strain-age cracking in Ni-based superalloys occrus when internal and external strain accumulation overlaps the $\gamma^{\prime}$ preicipitation strengthening. As the $\gamma^{\prime}$ precipitates out, lattice mismatch between the precipitate and matrix generates a stress. The precipitation consumes ducility of the material as the $\gamma^{\prime}$ fraction increases. The chance of cracking increases when thermally-induced or external stress from the printing process are generated. Hence, the amout of precipitate, the rate of precipitation, and develepment of residual stress are important factors to determine a trigger of strain-age cracking.

Figure 7 shows the evolution of $\gamma^{\prime}$ preicipitate and stress corresponding to thermal history obtained from the blade-1. The black- and blue- dashed line represent $\gamma^{\prime}$ fraction and max. principal stress, respectively. The total $\gamma^{\prime}$ fraction at the end of the process is almost identical as $32.8 \%$ in the lower, Fig.7(a) and upper reigion, Fig.7(b). Nevertherless, a substantial difference is found in the rate of precipitation. The precipitation begins at $737 \mathrm{~s}$ and reach to $29.7 \%$ at $1679 \mathrm{~s}(\Delta \mathrm{t}=942 \mathrm{~s})$ in the lower region while it starts $1268 \mathrm{~s}$ and reaches to $29.7 \%$ at $1725 \mathrm{~s}(\Delta \mathrm{t}=457 \mathrm{~s})$ in the upper region. The precipitation rate is about 2.1 times faster at the upper region. The cooling rate at the lower region is much slower than that at the upper region. Since the heat transfer happens through the spot-like bottom, the heat-input from the electron beam is larger that the heat-out to the substrate and the chamber. As a results, the heat is accumulated and the temperature increases. Consequently, the cooling rate becomes slower. As the part volume increases, the heat transfer direciton decomposes into $\mathrm{x}, \mathrm{y}$, and $\mathrm{z}$ direiction and the heat accumulation is released and cooling rate becoems faster. Correspondigly, more rapid precipitation occurs at the upper region.

The max.principal stress increases to $148 \mathrm{MPa}$ at the lower region and $189 \mathrm{MPa}$ at the upper region, respectivley. The heat accumulation at the lower region leads to slower stress development and a considerable stress relaxation. The tensile stress develops for $774 \mathrm{~s}$ in the lower region but for $332 \mathrm{~s}$ in the upper region. The concurrant rapid evolution in stress and precipitate indicates higher chance of strainage cracking in the upper region. The yield strength of IN738 is reported as $200 \mathrm{MPa}$ at $1000^{\circ} \mathrm{C}$ and $90 \mathrm{MPa}$ at $1100^{\circ} \mathrm{C}$ in prior literature [15]. The maximum stress at the lower region is about $25 \%$ lower than the yield strength, but the stress is close to the yield strength at the upper region at the corresponding temperature. Remember that the high fraction and rate of $\gamma^{\prime}$ leads to a significant reduction in ductility such that higher chance of cracking is expected in the upper region. 
(a) $39 \mathrm{~mm}$ in height

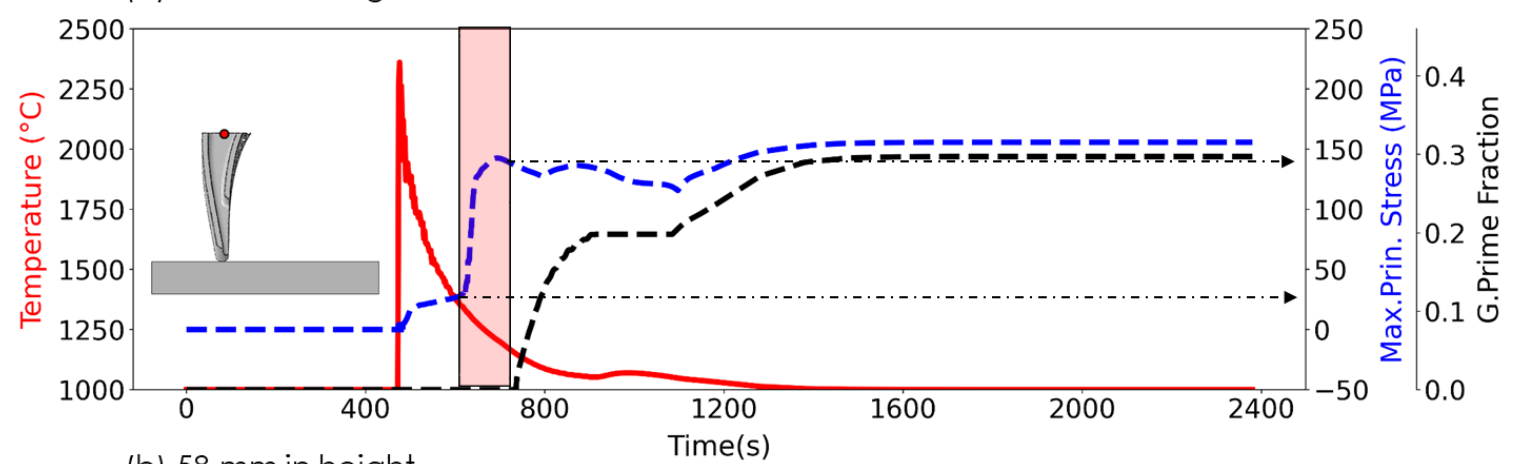

(b) $58 \mathrm{~mm}$ in height

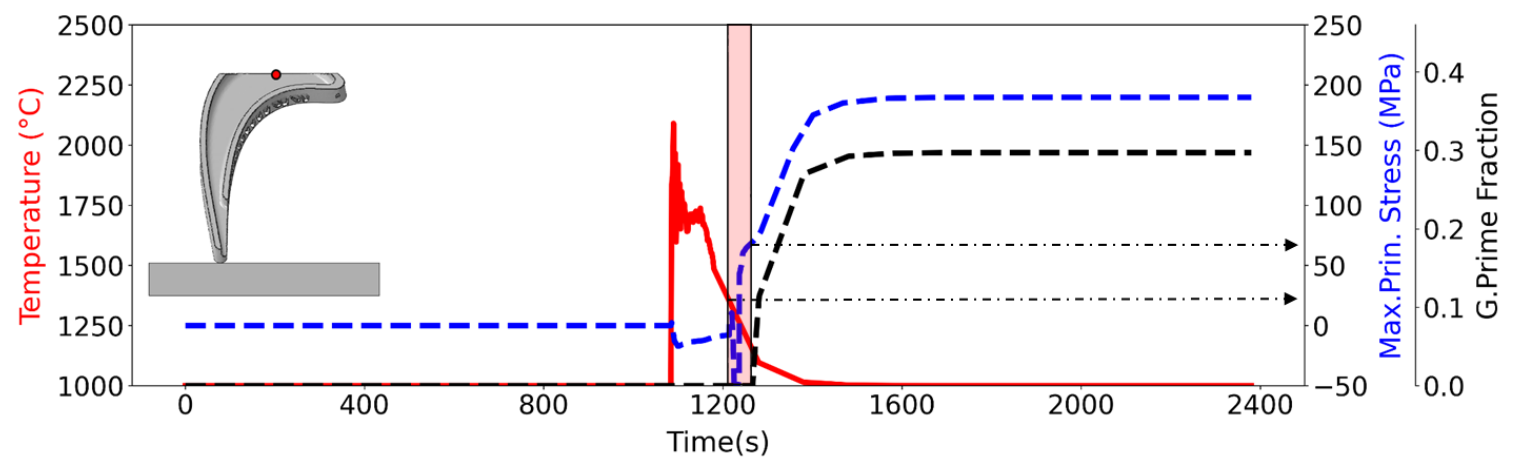

Figure 7. Thermal-microstructure-stress response in the blade-1

The evolutin of temperature-microstructure-stress for the blade- 2 is shown in Fig.8. The overall trend is similar to the blade-1. Faster evolution of $\gamma^{\prime}$ preicipitate and higher stress is found in the upper region while the stress is higher in the lower region compared to blade-1. Since the thickness of the blade2 is approxiamtely 2.2 times bigger than the blade- 1 , more heat due to higher-input into the volume is accumulated and so the stress relaxation becomes stronger in the lower region. In the upper region, rapid evolution of $\gamma^{\prime}$ in fraction and stress are observed. Like the blade-1, it indicates that cracking susceptiblity by strain-age cracking is higher in the upper region than the lower region. However, the hot cracking susceptibility is high in both geometries. 
(a) $39 \mathrm{~mm}$ in height

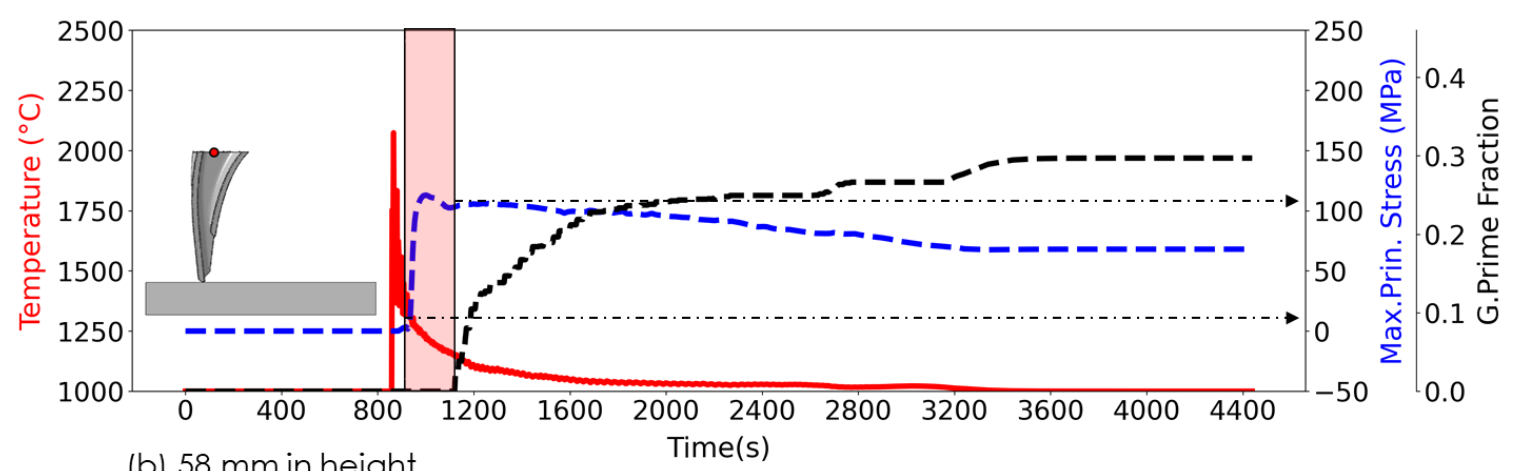

(b) $58 \mathrm{~mm}$ in height

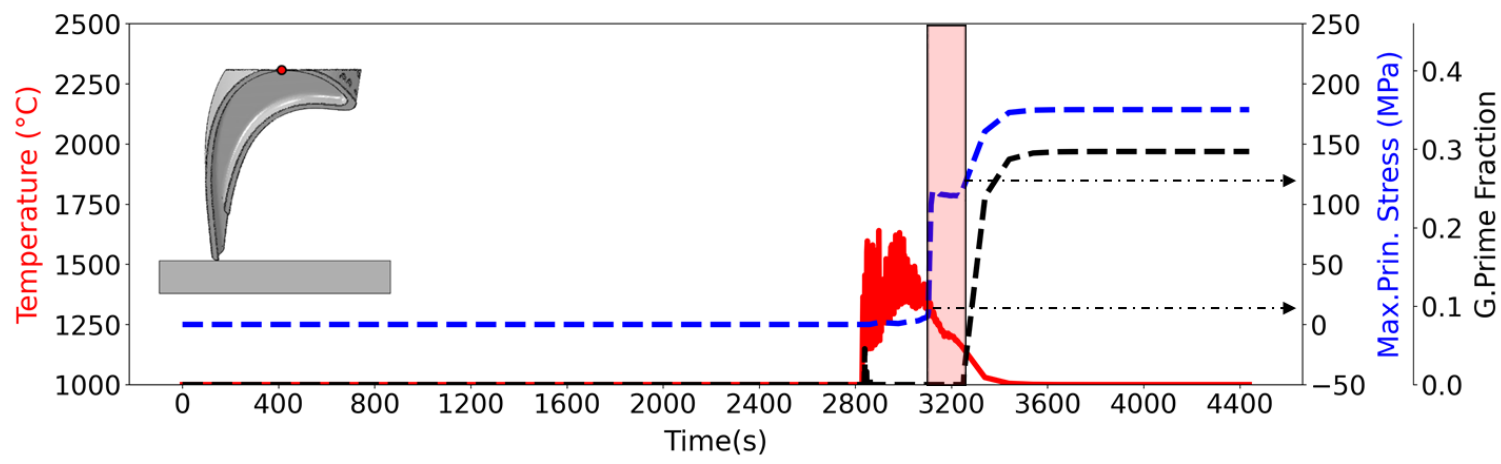

Figure 8. Dynamic evolution of thermal-microstructure-stress in the blade-2

\subsection{DISCUSSION}

We developed the modeling framework to determine the susceptibility in hot cracking and strain-age cracking for IN738 alloy. Yet, there are many other Ni-based superalloys remaining as non-printable such as Mar-M247. Figure 9(a) shows a list of printable, processible and non-printable Ni-based superalloys fabricated using EBM machine. Some of alloys on the list are typically known as non-weldable due to high $\gamma^{\prime}$ preicipitate wherein the printability criteia was estimated based on content of Ti+Al from welding literature Fig. 9(b). Such non-printable alloys like Rene and CM247 becomes printable by adjusting the printing parameters in a certain geomery. Still, Mar-M247 is extremly difficult to print without cracking issue. 
(a) List of Ni-based superalloys

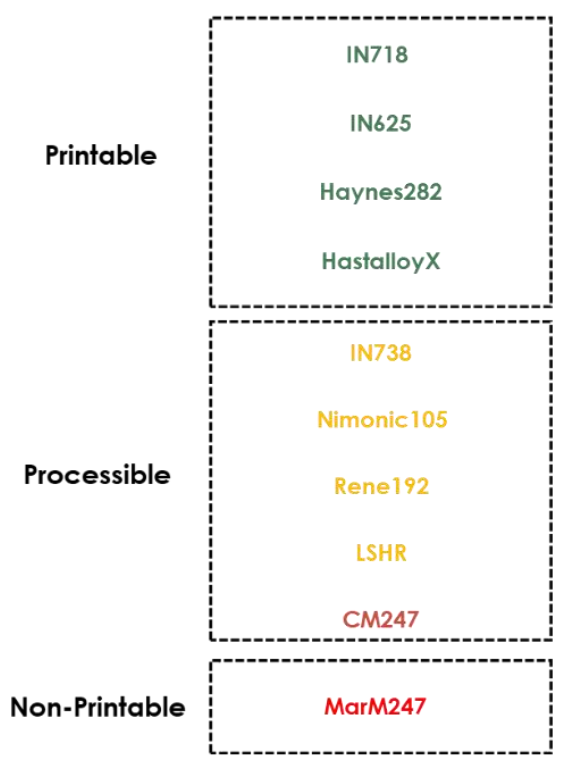

(b) Welding literature

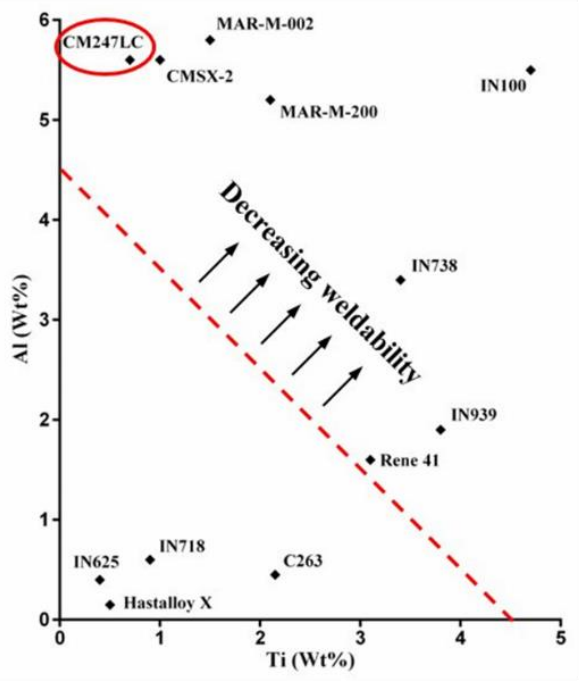

Ref. Fractal Scan Strategies for Selective Laser Melting of 'Unweldable' Nickel

Figure 9. Category of printable, processible, and non-printable Ni-based superalloys, (a) in EBM at ORNL and (b) in welding literature

The printability of Ni-based superalloy is heavily dependent on the $\gamma^{\prime}$ precipitation kinetics. The initiation and fraction of $\gamma^{\prime}$ precipite can be estimated from TTT diagram for various Ni-based superalloys to compare the precipitation kinetics. The TTT diagram for Hastelloy-X (printable), IN738LC (processible), CM-247LC (processible but limited), and Mar-M247 (non-printable) are plotted using JMatPro in Fig.10. The $\gamma^{\prime}$ precipitate starts when the cooling curve interpasses the $\gamma^{\prime}$ initiation curve (blue-dashed) and ends when it hits the $\gamma^{\prime}$ completion curve (red-dashed). The nose of curve shifts from the right to left and the trend agrees well with the level of printing difficulty. i.e., Hastealloy-X is the easiest whereas Mar-M247 is the hardest. It indicates that pushing the curve to the right can improve the alloy printability. 
(a) Hastelloy-X

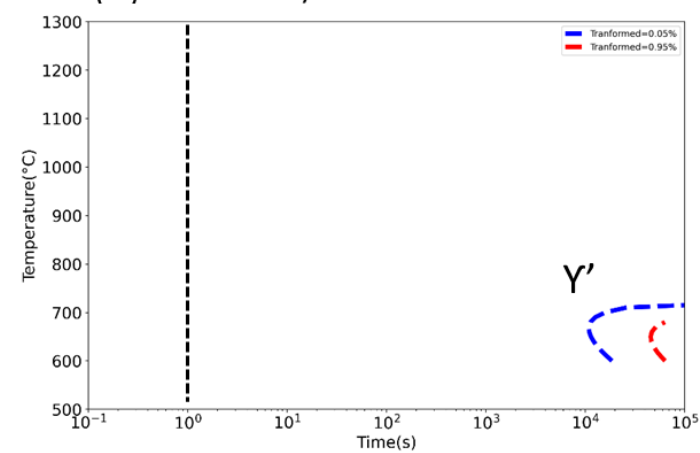

(c) CM247LC

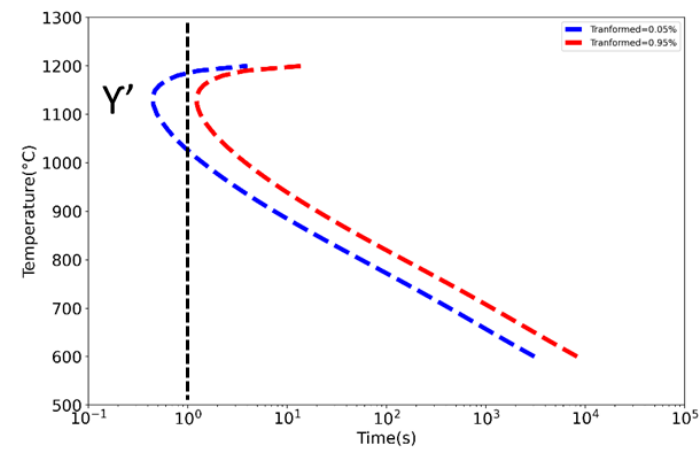

(b) IN738LC

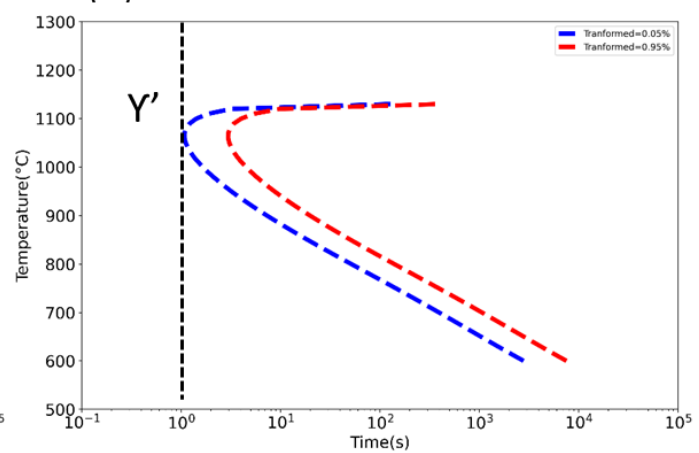

(d) Mar-M247

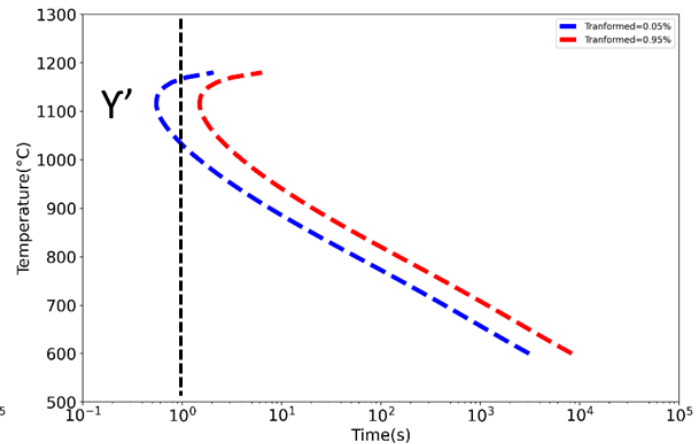

Figure 10. TTT diagram for printable, processible, and non-printable alloys, (a) Hastelloy-X (printable), (b) IN738LC (processible), (c) CM-247LC (processible but limited), and (d) Mar-M247 (non-printable)

The time-varying evolution of temperature-microstructure-stress for Mar-M247 are calculated and compared to the evolution of IN738 in Fig.11. A green dashed line represents the $\gamma^{\prime}$ evolution for MarM247. As seen in the blade-1 for IN738, the $\gamma^{\prime}$ precipitation is faster in the upper region than lower region, but the higher $\gamma^{\prime}$ fraction of $45 \%$ is predicted for Mar-M247. The time spent for $29.7 \%$ of $\gamma^{\prime}$ precipitation is $92 \mathrm{~s}$ for the lower region and 38s for the upper region. Compared to IN738 alloy, the precipitation rate of Mar-M247 is approximately 10 12 times faster. The differnce in fraction and rate proves why printing Mar-M247 is extremly difficult compared to other Ni-based superalloy. 
(a) $39 \mathrm{~mm}$ in height

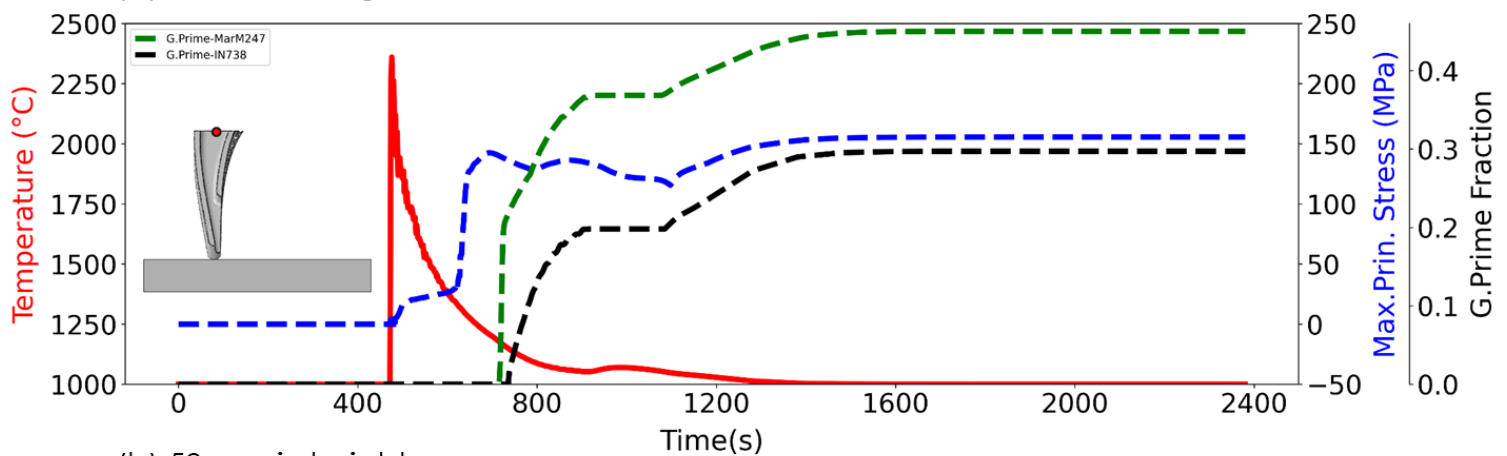

(b) $58 \mathrm{~mm}$ in height

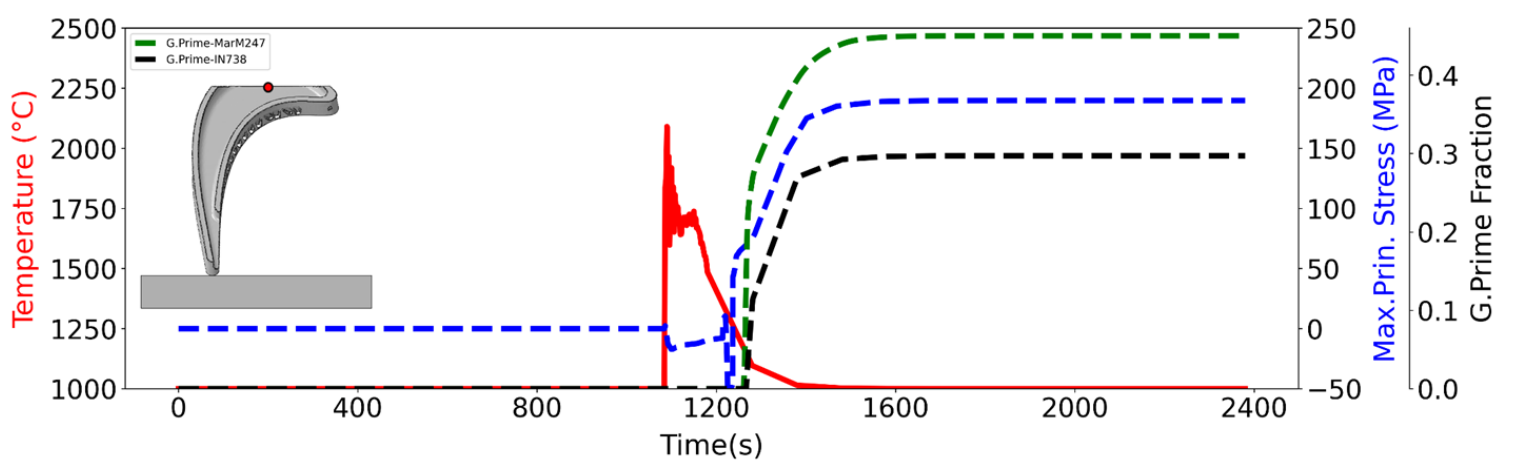

Figure 11. Comparison of Mar-M247 to IN738 in thermal-microstructure-stress response 
Ni-based superalloys typically contain various alloying elements up to ten or more including $\mathrm{Al}$, $\mathrm{Ti}$, $\mathrm{W}, \mathrm{Mo}, \mathrm{Cr}, \mathrm{Fe}, \mathrm{C}, \mathrm{B}, \mathrm{Co}, \mathrm{Zr}$ etc. $\mathrm{Al}$ and $\mathrm{Ti}$ are $\gamma^{\prime}$ former by combining with $\mathrm{Ni}$. $\mathrm{C}$ is benefitial for creep and rupture resistance. Mo and $\mathrm{W}$ are the refractory elements and strong carbide former. Co was substantially used in 70s, but replaced by Ni due to high cost. Althrough the role of Co is still in debate, it is known to decreases low temperature solubility of $\mathrm{Ti}$ and $\mathrm{Al}$ in the materix. Llewelyn et al. [16] reported that the extent of $\mathrm{Al}$ and Ti partitioning to the $\gamma^{\prime}$ phase is reduced when Co content is higher than $19 \%$.

A new alloy composition is suggested based on the literature. The composition of Co is ajdusted from $10 \%$ to $15 \%$ and $19 \%$ while the compoistion of $\mathrm{W}$ is reduced from $10 \%$ to $5 \%$ and $1 \%$. The TTT diagram for $\gamma^{\prime}$ precipiate was calculated using JMatPro in Fig.12. The black solid line incates the original TTT curve for the Mar-M247. The green and red dashed line represent 15\% Co and 19\% Co, repectively. The blue dashed line indicates the origianl curve for IN738. As the Co contents increases, the nose of TTT diagram shifts towards longer time and low temperature. The curve with $15 \%$ Co is placed in between the origianl Mar-M247 and IN738 curve. The more addition of Co to 19\% pushes the curve even below the curve for IN738. The prediction results indicate that the high addtion of Co suppress the high precipitation rate of $\gamma^{\prime}$ in Mar-M247 and potentially mitigates the change of cracking during printing. Therefore, substantial printability enhancement is expected for Mar-M247 alloy by high addtion of Co.

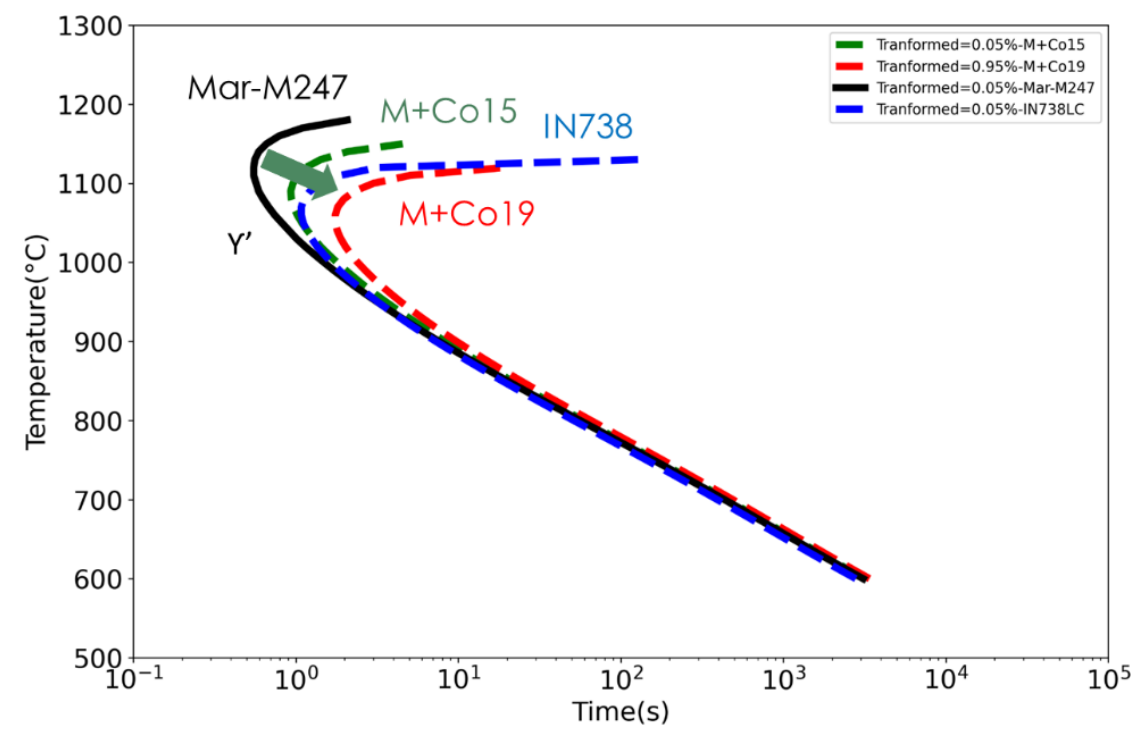

Figure 12. TTT diagram of In738 and Mar-M247. The nose of the curve is pushed to the right region by addition of Co.

\section{IMPACTS}

The developed computational framework fits into a broader process design and certification for gas turbine component. The work can be combined with alloy design and virtually support process design prior to actual manufacturing. It is estimated and reported that AM technology can lead to a considerable reduction in energy consumption by achieving lightweight and complex geometry in minimal waste of material and energy [17]. The established model will play a key role in shortening the designing and certification time and resultant reduction of lead time. 


\section{SUBJECT INVENTIONS}

There are no subject inventions associated with this CRADA.

\section{CONCLUSIONS}

The project was successfully completed and met all the targeted milestones to enable the next step in the development of non-printable Ni-based superalloys using the EBM AM process. The project developed a unique modeling capability to understand the prevalent cracking mechanisms in Ni-based superalloys, i.e., hot cracking and strain-age cracking, using a coupled tool of FEM and material model. Notable accomplishments for this project are:

- IN738 and Mar-M247 both show high susceptibility on hot- and strain-age cracking.

- Thicker geometric design of C2 shows an enhanced resistance to the strain-age cracking due to reduction of thermal stress

- Higher fraction and rate of $\gamma^{\prime}$ makes Mar-M247 more cracking susceptible compared to IN738.

- Alloying of Co pushes TTT curve to the slower precipitation region. Suppression of cracking is expected in Mar-M247.

- The developed model considering thermal history can be coupled with currently existing models of Cellular Automata (CA), Kinetic Monte Carlo (KMC) and Crystal Plasticity-FEM (CP-FEM) in the future to reveal process-microstructure-property relationship.

\section{REFERENCES}

[1] E.S. Huron, R.C. Reed, M.C. Hardy, M.J. Mills, R.E. Montero, P.D. Portella, J. Telesman, Superalloys 2012, John Wiley \& Sons2012.

[2] Y. Lee, M.M. Kirka, S. Kim, N. Sridharan, A. Okello, R.R. Dehoff, S.S. Babu, Asymmetric cracking in Mar-M247 alloy builds during electron beam powder bed fusion additive manufacturing, Metallurgical and Materials Transactions A 49(10) (2018) 5065-5079.

[3] S. Kou, Welding Metallurgy Wiley Interscience, Hoboken NJ (2003).

[4] S. Babu, S. David, J. Park, J. Vitek, Joining of nickel base superalloy single crystals, Science and technology of welding and joining 9(1) (2004) 1-12.

[5] C. Cross, On the origin of weld solidification cracking, Hot cracking phenomena in welds, Springer2005, pp. 3-18.

[6] J.C. Lippold, Recent developments in weldability testing for advanced materials, ASM InternationalJoining of Advanced and Specialty Materials. VII (2005).

[7] M. Rowe, Ranking the resistance of wrought superalloys to strain-age cracking, Welding journal 85(2) (2006) $27 \mathrm{~s}-33 \mathrm{~s}$.

[8] S.J. Owen, T.R. Shelton, Validation of grid-based hex meshes with computational solid mechanics, Proceedings of the 22nd International Meshing Roundtable, Springer2014, pp. 39-56.

[9] B.C. Kandpal, A. Chutani, A. Gulia, C. Sadanna, A review on Jominy test and determination of effect of alloying elements on hardenability of steel using Jominy end quench test, International Journal of Advances in Engineering \& Technology 1(3) (2011) 65.

[10] ThermoCalc., http://www.thermocalc.com/. 
[11] N. Saunders, U. Guo, X. Li, A. Miodownik, J.-P. Schillé, Using JMatPro to model materials properties and behavior, JOM 55(12) (2003) 60-65.

[12] A. Crespo, Modelling of heat transfer and phase transformations in the rapid manufacturing of titanium components, InTech2011.

[13] Q. Zhang, J. Xie, Z. Gao, T. London, D. Griffiths, V. Oancea, A metallurgical phase transformation framework applied to SLM additive manufacturing processes, Materials \& Design 166 (2019) 107618.

[14] C.C. Murgau, R. Pederson, L.-E. Lindgren, A model for Ti-6Al-4V microstructure evolution for arbitrary temperature changes, Modelling and Simulation in Materials Science and Engineering 20(5) (2012) 055006.

[15] Y. Lee, M.M. Kirka, J. Ferguson, V.C. Paquit, Correlations of cracking with scan strategy and build geometry in electron beam powder bed additive manufacturing, Additive Manufacturing 32 (2020) 101031.

[16] S. Llewelyn, K. Christofidou, V. Araullo-Peters, N. Jones, M. Hardy, E. Marquis, H. Stone, The effect of Ni: Co ratio on the elemental phase partitioning in $\gamma-\gamma^{\prime} \mathrm{Ni}-\mathrm{Co}-\mathrm{Al}-\mathrm{Ti}-\mathrm{Cr}$ alloys, Acta Materialia 131 (2017) 296-304.

[17] M. Baumers, C. Tuck, R. Wildman, I. Ashcroft, R. Hague, Energy inputs to additive manufacturing: does capacity utilization matter, Eos 1000(270) (2011) 30-40. 